\title{
Telecommunication and an information infrastructure in China
}

\author{
W. G. Chismar \\ University of Hawaii \\ College of Business Administration \\ 2404 Maile Way \\ Honolulu HI 96822 \\ (808) 956-7276 telephone \\ (808) 956-9889 fax \\ chismar@dscience.cba.hawaii.edu
}

\begin{abstract}
International telephony and computer networks now play a critical role in managing an international company. Unfortunately for companies doing business in China, reliable connections to these networks have only recently become available in the major cities and are non existent in most of the country. In response, the Chinese government has made telecommunications a priority in its efforts to promote economic development; but its efforts have been hindered by conflicting political and business interests. In this paper we look at the two aspects of the development of the information infrastructure in China: telecommunications development and the Internet. Currently the central government maintains tight control over telecommunications development, but this control is quickly breaking down. The Internet in China has been developing in a totally separate environment, largely out of the control of the central government. While control over telecommunications appears to be relaxing, control over the Internet has suddenly tightened. This paper presents the evolution of these policies.
\end{abstract}

China, Telecommunications, Internet, Policy

\section{Keywords}




\section{INTRODUCTION}

Access to information and connections to international locations are key to the development of the economy in China. In attempting to sustain very rapid economic development, China is luring in foreign companies at an amazing rate. Unfortunately for companies doing business in China, reliable connections to computer and telecommunication networks have only recently become available in the major cities and are non existent in most of the country. In response, the Chinese government has made telecommunications a priority in its efforts to promote economic development; but its efforts have been hindered by conflicting political and business interests.

The Chinese political system is based on a tradition of strong central control of information and a society closed to foreign influences. With Deng Xiaoping's reforms in 1979, China moved toward a more open door policy. As this policy created rapid economic growth in cities along the eastern coast and in the south of China, it became clear that China's telecommunication infrastructure was woefully inadequate. In addition, it was clear that the strict monopolistic control of telecommunications could not respond fast enough the demands placed on it. In the 1990's China began to reform its telecommunication policies, though it maintained strong regulations.

In contrast, the Internet in China evolved very rapidly in the 1990's, largely out of the control of the central government. Networks from academic and research organizations linked together and then opened gateways to the Internet. But the openness brought by the Internet would not long be tolerated by the central government. Recent policy changes have drastically changed the nature of the Internet in China. Control over the Internet is being placed in ministries traditionally in charge of telecommunications.

In the next section of this paper, we look at the recent development and structure of telecommunications in China. This is followed by a parallel presentation of the development of the Internet in China. The final section discusses the policies of the Chinese government and the merger of the Internet and telecommunications control.

\section{TELECOMMUNICATIONS}

The roles of the major players in China's telecommunication industry are undergoing a revolution of sorts. For many years, the Ministry of Post and Telecommunications represented the government's monopoly in three roles: the national public service provider; policy maker and regulator of telecommunications at the national, provincial, and municipal levels; and equipment manufacturing (Tan 1994). In the face of rapidly expanding demand for telecommunication services, the MPT, like so many other telecommunication monopolies, has been very slow to respond. Directly under the MPT are the provincial Posts and Telephone Administrations (PTAs). Reporting to the PTAs are the city Posts and Telephone Bureaus (PTB), which, in the face of the MPT's slowness to respond to market demands, have been exhibiting increasing degrees of independence from the MPT. Since 1978 they have been able to retain part of their revenue for reinvestment and encouraged to seek investments (Tan 1994). The southern PTBs of Guandong and Jiangsu are quite autonomous, driven by the greater economic activity in the south.

In addition to the MPT with its public networks, several ministries, notably those of railways (MOR), electronic industries (MEI), and power (MOP), and the People's Liberation Army (PLA) have been allowed to develop, own, and operate their own telecommunication networks. By law, they have been prohibited from providing public services over their networks. However, as it became clear that the MPT was unable to meet the telecommunications demands of China, the 
ministries, PLA, and PTBs began to enter the public telecommunications market. The MPT has shown a willingness to ignore or a political inability to counter these activities (Bien 1994).

In 1992, the Ministry of Electronics Industry (MEI) joined with the Ministry of Railways and the Ministry of Electronics to form a "united telecommunications company," Lian Tong, also known as Unicom and more recently, China Com. Lian Tong was formed primarily as a data network operator, but with clear intentions of competing directly with MPT on private networks (Tan 1994). In light of opposition from the MPT and the reiteration of MPTs monopoly by the State Council, Lian Tong got off to a very slow start.

In September of 1993, the MEI and Lian Tong formed a new company, Ji Tong. Ji Tong also has a list of minor shareholders consisting of about 20 Chinese companies. MEI, under the pro-telecomreform leadership of $\mathrm{Hu}$ Qili, was positioning itself to confront MPTs monopoly by having Lian Tong established as the owner of a national data network and Ji Tong as the provider of services over the network (Business China, 9/19/94).

In December of 1993, it appeared that the State Council had given approval to Lian Tong to establish a second national voice and fax network. However, the MPT seem reluctant to accept a second national network and doubts grew over Lian Tong's long term viability. Despite this opposition, Lian Tong is clearly building a long distance network based on the railway ministry's existing network (Anonymous 1994).

When Lian Tong gained approval to compete with MPT, the need for Ji Tong reduced and Ji Tong lost the active support of the MEI (Business China, 9/19/94). With Lian Tong focusing on the bread-and-butter business of public voice and fax services, Ji Tong differentiated itself by focusing on more specialized services. In a rapid start, Ji Tong signed joint-venture agreements with foreign companies, including BellSouth for network planning and engineering services and IBM. It has undertaken some large projects, including the Golden Gate, an electronic data interchange network (EDI), the Golden Card, a national credit card clearing system, and the Golden Bridge, links among large national data centers. (Hendry 1994).

In 1994 China began a reorganization of the MPT which included the separation of roles of network operator and regulator. The Directorate General of Telecommunications, formerly under the MPT, is now the operator of China's public telecommunication networks, while the MPT it will remain the national regulator of the networks with the authority to license operators (Anonymous 1994). According to MPT's chief of information, the reorganization will lay the groundwork for setting up a national telecommunications service company with regional subsidiaries formed out of the existing PTBs (Hendry 1994).

China's computer networks and links into the Internet have been evolving since the late 1980's, mostly independent of the telecommunication networks and direct central government control. Most of the networks serve the academic and research communities, although commercial access to the Internet has recently become available. There are currently three major networks with access to the Internet: ChinaNet/NCFC, CERNET, and ChinaNET. In addition, several smaller networks are setting up links to the Internet. 


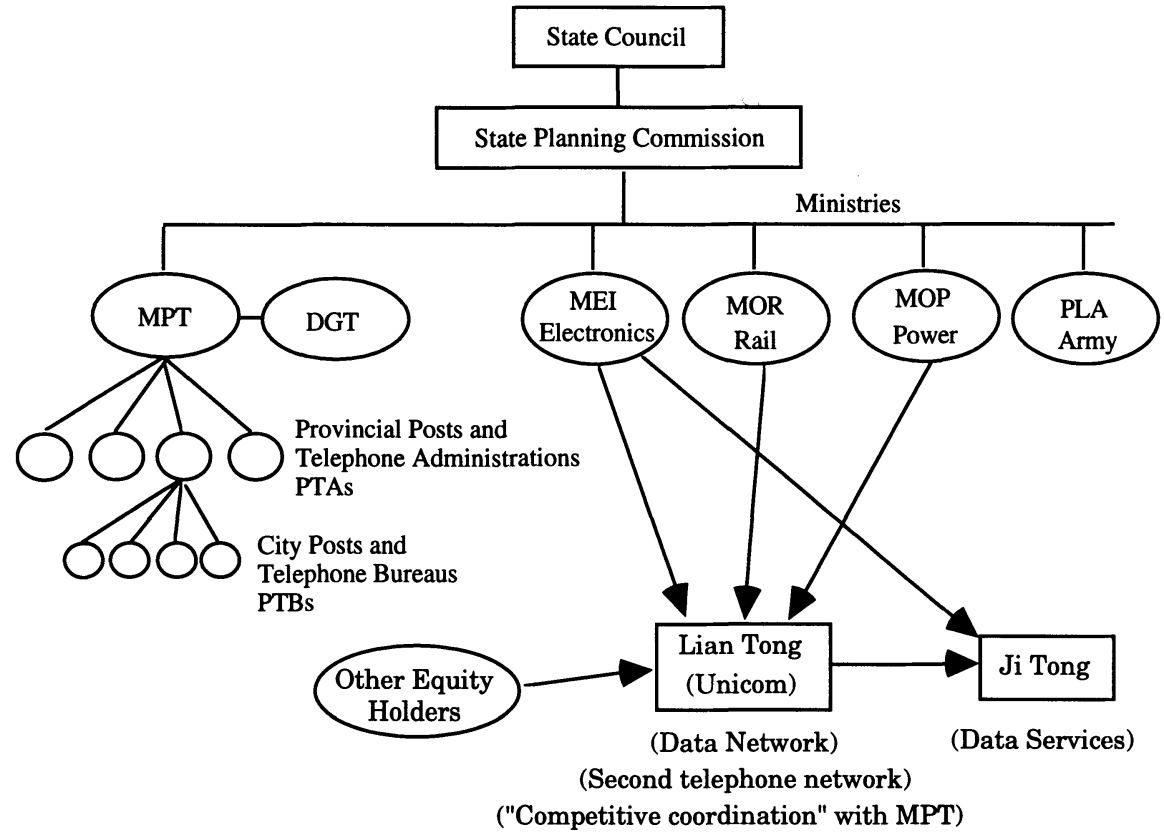

Figure 1 Telecommunications players in China.

\subsection{ChinaNet/NCFC}

In 1989 the World Bank and China's State Planning Commission funded development of the National Computing and Networking Facility of China (NCFC). Completed in 1993, the NFCF connected networks of the China Academy of Science (CASnet), Peking University (PUnet), and Tsinghua University (TUnet). In 1993, the IHEPnet (Institute for High Energy Physics), part of the CASnet, became the first Chinese regional network fully connected to the Internet via AT\&T leased lines to the Stanford Linear Accelerator Center. In May of 1994, NCFC linked to NSFNET via a Sprint satellite link and got the country-level domain name ".CN".

While its original goal was to allow the three institutions to share computing facilities, NCFC became the core of ChinaNet, which connected the Beijing metropolitan area and other cities. Administration and operation of the ChinaNet is dominated by the China Academy of Science. In addition to NCFC, ChinaNet includes USTCnet (University of Science and Technology of China), SSTCnet (State Science and Technology Commission network), and some 20 other science-related networks. The Macau regional network and Hong Kong Chinese University network were also connected to ChinaNet. 


\subsection{CERNET}

The China Education and Research Network (CERNET) is funded by the Chinese government and directly managed by the Chinese Sate Education Commission. With development starting in July of 1994, CERNET was modeled after the US. NSFNet project. Its goal is to link all of China's universities and eventually, other lower level schools. This includes some 1,200 universities, more than 39,000 middle schools, and 160,000 primary schools. If the proposed schedule is followed, CERNET will soon be the largest educational and research network in the world.

CERNET has a three-layer hierarchical structure: nation-wide backbone with international links, regional networks, and campus networks. The backbone nodes include ten key universities in Beijing, Shanghai, Guangzhou, Nanjing, Xian, Wuhan, Chengdu, and Shenyang. While its original link to the Internet was through NCFC, it now has an independent link to the United States, with two more soon to be added, one to Europe and one to the Asia Pacific region.

\subsection{ChinaNET}

China Internet (ChinaNET) is a nation-wide, general purpose public network managed by the MPT. It has links in more than 600 cities with plans to cover the country. ChinaNET evolved from the data and telephone networks of the MPT (CHINAPAC, CHINADDN, and PSTN) and began operating in the spring of 1995 . Provincial telecommunication administrations manage the operation of the ChinaNET. The Beijing Telecommunication Administration manages the high speed fiber optic link among three gateways: Beijing, Shanghai, and Guangzhou. The link to the Internet is via SprintLink to the USA.

\subsection{Other networks}

Several smaller networks have also set up links to the Internet. The Beijing University of Chemical Technology (BUCT) connected to the Internet in September of 1994 through the Beijing Telecommunication Administration to the CAREN (Consortium of Asian Research and Education Network) and JVNCnet (John Von Neumann Center network). The Nanjing International Internet (NJNET) opened in April of 1995 with the goal of facilitating the city's science and technology development. It is now providing email services and plans to provide comprehensive information services. Other networks will likely follow.

\subsection{Cooperation among internet players}

China's Internet efforts have been uncoordinated and lacking in leadership for top government agencies. This is most likely the result of a lack of funds among the smaller institutions and a lack of interest and manpower by the State Planning Commission which is funding the NCFC (Tan 1996). In an effort to provide some direction, the Chinese Internet Development Policy and Technology Examination Conference was held in Beijing in August of 1995.

The participants to the conference were Chinese bureaucrats from many fields, domestic and foreign specialists, and some industry managers. The impact of the conference will be limited by the fact that it is a temporary organization without solid financial and administrative bases (Tan 1996). The conference covered

- A development vision for the Chinese Internet 
- Current government policy

- Experiences and achievements of the Internet in developed countries

- Foreign advise to China

- The exchange of Internet technology and education.

\section{POLICY ISSUES}

Since Deng Xiaoping's reforms in 1979 China has striven to operate a "socialist market economy." Under such a system greater economic autonomy has been given to local governments, such as the special economic zones, and to business enterprises. However, this autonomy directly conflicts with the government's wish to maintain tight control over China's political, social, and industrial development. A critical component to the success of the Chinese Communist Party system has been strict control of communication within the country. A critical component to the success of a liberalize market economy is access to the means of communication, such as computer networks and international links, and the freedom to use them as, when, and how they are required (Ure 1995).

As in many other countries, the development of communication technologies and of the Internet have outpaced the regulatory processes of the government. But, in China this problem is compounded by the contradiction between the political and economics systems. The result has been a lot of confusion and uncertainty about China's policies with respect to telecommunication and the Internet, and a sever shortage of telecommunication capabilities necessary to support economic growth.

Though the official policy of the central government keeps regulatory control over all telecommunications with the MPT, the MPT has been unable or unwilling to enforce strict control. Faced with rapid economic development, poor telecommunications infrastructure, and the slowness of the MPT to respond, provincial and city governments are taking steps on their own to improve their telecommunications infrastructure. Faced with economic opportunities to capitalized on their existing private networks, ministries other than the MPT are selling services to the public. The PLA is selling satellite services; the city of Shanghai is installing its own data networks to support commerce; Ji Tong and Lian Tong are negotiating with foreign telecommunication companies.

One of the biggest issues dividing the central government and other units relates to the involvement of foreign companies in the delivery of telecommunication services. The expertise of foreign companies in the design, management, and operation of telecommunication networks and services would greatly accelerate China's development. While individual PTBs and other Chinese enterprises are speaking with foreign telecommunication companies, the MPT has reiterated its intent to enforce laws against foreign involvement in the ownership or operations of telecommunication networks.

While the Chinese government's policy toward telecommunications is one of strict central control, its attitude towards electronic bulletin boards and the Internet in general have been surprisingly relaxed, particularly in light of its massive funding of efforts like the NCFC and the CERNET (Johnson 1995). Announcements throughout 1995 from the Minister of State Planning Commission and other official committees have stressed the importance of the information industry in fueling rapid economic development and the need for investment in basic information infrastructure. All of this emphasis on rapid growth and lack of rigid controls should not be mistaken for a long term policy of information openness.

The Chinese government, through the MPT, has begun to show signs of taking over control of the Internet in China. The minister of the MPT, Wu Jichuan, has repeatedly stated that China will 
certainly need to impose some monitoring and restrictions over the flow of information on the Internet. He has added that China has the capability of imposing restrictions (Lu 1995). On February 4, 1996, the official Xinhua news agency stated that all computer information networks must use international channels provided by the MPT to hook up to networks abroad. All existing interactive networks, after liquidation, will be subject to management by the MPT, the MEI, the State Education Commission, and the Chinese Academy of Sciences ( $\mathrm{Li}$ 1996). The exact implications of these restrictions remain to be seen.

These new regulations are part of a series of recent high level initiatives to control and censor information entering China from foreign news and information services. In one case, the State Council ordered foreign vendors of economic information to submit to censorship by the Communist Party's Xinhua news agency (Li 1996). Such actions clearly mark a step backward in China's drive for a more market-oriented economy.

We can expect to see a continued move toward centralizing regulatory power over both telecommunication and the Internet in the MPT. Along with this move will come increased isolation of China from the rest of the world. On the other hand, the pressure for reform will also continue to come from sectors of the country interested in economic development. With a large infrastructure and access to the Internet in place, and with the rapid economic growth over the past ten years, the current moves backwards may be temporary. But, firms interested in doing business in China should not underestimate that country's resolve to control information flows and business planning must be adjusted accordingly.

\section{ACKNOWLEDGMENT}

This research was partially supported by a grant from the Center for International Business Education and Research at the University of Hawaii.

\section{REFERENCES}

Anonymous (1994), "Business China Supplement: Telecoms," The Economist Intelligent Unit, May. Bien, W. (1994) "The Prospects for Foreign Investment in China's Telecommunication Service Sector," research report, Communications and Journalism Program East-West Center.

Hendry, S. (1994) "Sunset on a monopoly?" China Trade Report, p. 2, March.

Johnson, A. and Liu, J. (1995) "China Opens the Internet," CND-Global, April 10.

Li, L. and Macartney, J. (1996) "Chinese Government Issues New Rules to Regulate Internet Access," China News Digest, February 6.

Lu, J. (1995) "Internet Becomes Popular in China," China Time Weekly, No. 200.

Tan, Z. (1996) "Internet in China: Growth, Competition and Policy," Proceedings of the 18th Annual Pacific Telecommunications Conference, Pacific Telecommunications Council, Honolulu, January.

Tan, Z. (1994) "Challenges to the MPT's monopoly," Telecommunications Policy, 18 (3), 174-181.

Ure, J. (1995) "Telecommunications in China and the Four Dragons," in Telecommunications in Asia: Policy, Planning and Development, Ure, J. (Editor), Hong Kong University Press, Hong Kong, 11-48. 


\section{BIOGRAPHY}

William Chismar, an associate professor and chairman of Decision Sciences at the University of Hawaii, received degrees in philosophy, mathematics, and system sciences from Carnegie Mellon University. His research interests include the roles of information technology in international business, the use of information technology in structuring organizations, and the economics of information systems. His studies of international telecommunications have taken him throughout East and Southeast Asia and Australia. He is currently working on a study of telecommunication policy and the internet in China, and a study of the use of information technology for reengineering in the healthcare industry. 